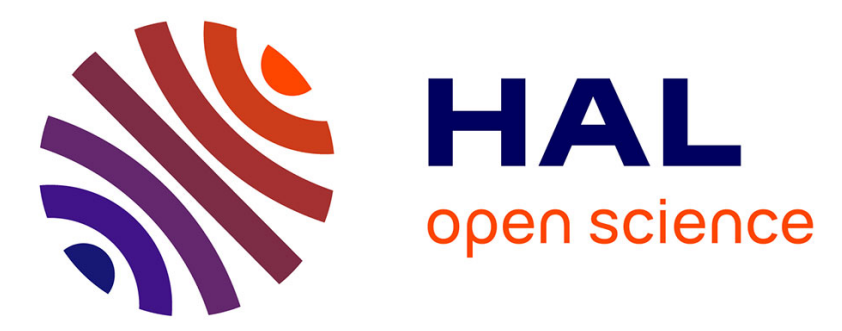

\title{
Elastoplastic self-consistent modelisation of internal stresses in rolled Zr702a
}

David Gloaguen, Marc François, Ronald Guillen, Jean Royer

\section{To cite this version:}

David Gloaguen, Marc François, Ronald Guillen, Jean Royer. Elastoplastic self-consistent modelisation of internal stresses in rolled Zr702a. Materials Science Forum, 2002, 404-407, pp.281-287. 10.4028/www.scientific.net/MSF.404-407.281 . hal-01006792

\section{HAL Id: hal-01006792 \\ https://hal.science/hal-01006792}

Submitted on 5 Dec 2018

HAL is a multi-disciplinary open access archive for the deposit and dissemination of scientific research documents, whether they are published or not. The documents may come from teaching and research institutions in France or abroad, or from public or private research centers.
L'archive ouverte pluridisciplinaire HAL, est destinée au dépôt et à la diffusion de documents scientifiques de niveau recherche, publiés ou non, émanant des établissements d'enseignement et de recherche français ou étrangers, des laboratoires publics ou privés. 


\title{
Elastoplastic Self-Consistent Modelisation Of Internal Stresses in Rolled Zr702 $\alpha$
}

\author{
D.Gloaguen ${ }^{1+}$, M.François $^{2}$, R.Guillen', J.Royer ${ }^{3}$ \\ ${ }^{1}$ Laboratoire d'Applications des Matériaux à la Mécanique - LAMM, I.U.T. Saint-Nazaire, C.R.T.T., \\ B.P 406, 44602 Saint-Nazaire cedex, France. \\ ${ }^{2}$ Laboratoire des Systèmes Mécaniques et d'Ingénierie Simultanée (LASMIS), Université de \\ Technologie de Troyes, 12 rue Marie Curie, BP2060, 10010 Troyes, France. \\ ${ }^{3}$ Laboratoire Mécanique et Matériaux (LMM), Ecole Centrale de Nantes, 1 rue de la Noë, \\ BP92101, 44321 Nantes cedex 03, France.
}

+ Corresponding author. Tel. :+33-2 401726 28; e-mail: gloaguen@lamm.univ-nantes.fr

Keywords: Zirconium, elastoplastic self-consistent model, internal stresses, X-ray diffraction, plastic anisotropy,

\begin{abstract}
Internal stresses due to anisotropic thermal and plastic properties were investigated in a rolled zirconium- $\alpha$. The thermal stresses induced by a cooling process were predicted using a selfconsistent model and compared with experimental results obtained by $\mathrm{X}$-ray diffraction. The study of the elastoplastic response after uniaxial loading was performed along the rolling and the transverse direction of the sheet. Using an elastoplastic self-consistent model, the predicted results were compared with X-ray diffraction and mechanical tests. Theoretical and experimental results agree in their tendencies. The confrontation between $\varepsilon_{\phi \psi}$ vs. $\sin ^{2} \psi$ and simulations confirms that prismatic slip is the main active deformation mode.
\end{abstract}

\section{Introduction}

Zirconium alloys are widely used in nuclear industry because they exhibit a high resistance to corrosion, a good thermal conductivity and a low neutron cross section. They have a hexagonal close packed structure at room temperature. These alloys present anisotropic thermal, elastic and plastic properties at mesoscopic (grain) and macroscopic levels. These properties and the crystallographic texture explain the appearance and the development of internal stresses when an elastoplastic deformation is introduced. Two types of internal stresses can be distinguished :

- Thermal internal stresses, which may arise from thermal anisotropy. During the cooling process after a heat treatment, each grain is subjected to a contraction which depends on crystallographic direction. Elastic strain (and stress) must be present to maintain the compatibility of total strain between adjacent grains. Thermal stresses can modify the macroscopic elastoplastic response of the material, particularly for zirconium alloys [1].

- Mechanical internal stresses, induced by the elastoplastic anisotropy and the requirement of compatibility.

The purpose of the present work is to make a complete study concerning the development and the evolution of internal strain introduced by tensile tests in rolled textured polycristalline $\mathrm{Zr}-\alpha$ after a cooling process. Self consistent models (thermoelastic and elastoplastic) were used to simulate the thermal and the tensile response of samples tested along the rolling (RD) and the transverse (TD) directions of the sheet. In this study, the predicted residual stresses in a rolled $\mathrm{Zr}-\alpha$ have been compared with experimental data provided by X-ray diffraction experiments in order to obtain more informations about the different factors responsible for the appearance of residual elastic mesostrains. This confrontation allows a better understanding and interpretation of X-ray diffraction and mechanical results. X-ray diffraction technique is one of the most used for the characterization of the mechanical state at mesoscopic level of the samples. 


\section{Experimental procedure}

The investigated material is a commercially pure zirconium- $\alpha$ ( $\mathrm{Zr702}$ ). Its chemical composition is given in Table 1. The metallographic examination of the annealed material revealed an average grain size of approximately $20 \mu \mathrm{m}$.

\begin{tabular}{|c|c|c|c|c|c|c|}
\hline Element & $\mathrm{O}$ & $\mathrm{C}$ & $\mathrm{Fe}+\mathrm{Cr}$ & $\mathrm{H}$ & $\mathrm{N}$ & $\mathrm{Hf}$ \\
\hline Wt. \% & 0.14 & 0.02 & 0.08 & $<0.0003$ & 0.004 & 0.4 \\
\hline
\end{tabular}

Table 1 : Chemical composition of Zirconium sheet

\section{II.1. Mechanical testing}

To analyse the influence of loading direction and texture on the mechanical response of the material, samples of dimensions $2 \times 1.5 \times 43.4 \mathrm{~mm}^{3}$ were cut from the rolling (RD) and the transverse directions (TD) of the sheet. The specimens were submitted to uniaxial tensile tests at room temperature, at a constant strain rate of $3.810^{-3} \mathrm{~s}^{-1}$ with different total strains. Samples were 1 and 2 $\%$ deformed of in the two loading directions. The tensile loading curves are depicted in Figure 1.

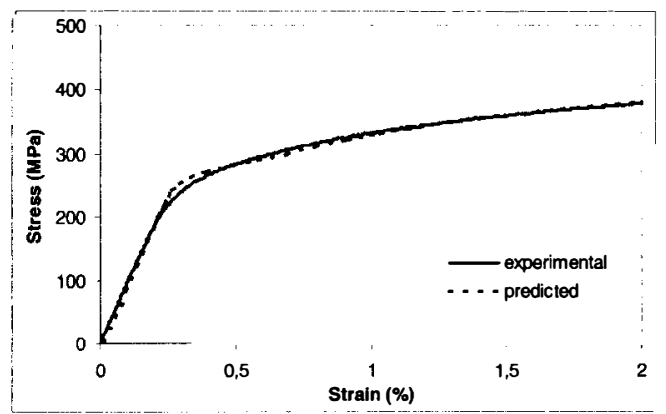

(a)

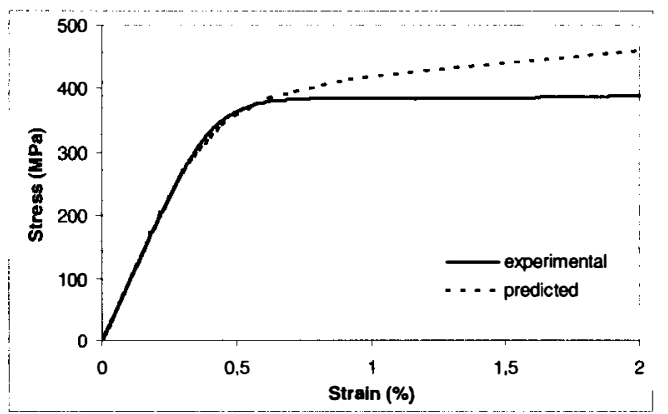

(b)

Figure 1: Experimental and calculated stress-strain curves for a tensile test in the rolling (a) and transverse direction (b) of the sample

\section{II.2. Stress measurements by $\mathrm{X}$-ray diffraction technique}

The experiments were carried out in two stages:

- Characterization of internal stresses due to thermal anisotropy in an undeformed sample after a thermal treatment at $650^{\circ} \mathrm{C}$ during $4.5 \mathrm{~h}$.

- Determination of the evolution of internal stresses due to plastic anisotropy for samples deformed samples by uniaxial tensile both along rolling and transverse directions. Measurements were carried out in the unloaded state.

These experiments were carried out on a D500 SIEMENS goniometer with a $\mathrm{Cr} \mathrm{K}_{\alpha}$ radiation. An $\Omega$ goniometric assembly with a scintillation detector was used. Two plane families were studied : $\{10 \overline{1} 4\}$ at $2 \theta=156,7^{\circ}$ and $\{20 \overline{2} 2\}$ at $2 \theta=137,2^{\circ}$. Diffractograms were recorded for fifteen tilt angles $\psi$ varying between -45 and $45^{\circ}$ and for azimuth angles $\phi=0,45$ and $90^{\circ}$. The direction $\phi=$ $0^{\circ}$ corresponds to the tensile direction. The X-ray beam output collimator has $0.5 \mathrm{~mm}$ diameter and a diffracted-beam slit limits the equatorial divergence to an angle of $0,6^{\circ}$. The sample shows a typical texture of rolled Zirconium. The basal poles are preferentially oriented at an angle of $32^{\circ}$ from the normal direction towards the transverse direction, while the prism poles exhibit a weak maximum in the rolling direction.

To avoid surface effect because of the mechanical history of the sheet or oxygen contamination during the thermal treatment, the specimens were electrochemically polished. Electro-polishing was carried out at $298 \mathrm{~K}$ under a potential difference of $30 \mathrm{~V}$ in a $10 \%$ perchloric acid $+90 \%$ acetic acid solution. Stress measurements by X-ray diffraction have been made at a depth of $100 \mu \mathrm{m}$. The 
experimental data from the mechanical tests and X-ray diffraction are presented and compared with the results from our model in the fourth section.

\section{Self-Consistent Modeling}

We consider that thermal contractions do not introduce plastic deformation in the material during the cooling process [1]. In this case, a thermoelastic formulation is sufficient to simulate the evolution of thermal stresses associated with cooling. An elastoplastic self-consistent scheme was then used to predict the mechanical behaviour of titanium polycristal under an uniaxial tension.

The model used for our simulations was presented in a previous work [2]. More details can be found in references $[3,4]$.

The self consistent model is based on the following assumptions :

- Each grain is considered as a spherical inclusion embedded in a Homogeneous Effective Medium (HEM) having the average properties of the aggregate.

- The mesoscopic stress $\sigma$ and the mesoscopic strain $\varepsilon$ in the inclusion are homogeneous.

- The overall response of the material is determined from averaging the microscopic terms ( $\sigma$, $\varepsilon)$ over a representative set of orientations.

- The macroscopic stress $\Sigma$ and macroscopic strain $\mathbf{E}$ are considered as uniform. The properties of the medium are initially undetermined and must be solved by iterations. Each grain is treated as an inhomogeneity with elastic (c) and thermal $(\alpha)$ constants, slip and twin mechanisms characteristic of a single crystal.

- The texture is known, the polycristal is represented by a weighted discrete distribution of orientations (Euler angles $\left(\varphi_{1} \phi \varphi_{2}\right)$ ). Lattice rotation (reorientation by slip and twinning) and texture changes are incorporated in the model.

\section{III.1. Thermal residual stresses}

The thermal strains due to cooling from annealing temperature to room temperature are calculated with the thermoelastic model. We suppose that the polycristal is stress-free at $923 \mathrm{~K}$. The crystallographic orientation distribution function of the sample was calculated from the pole figures of the sample. A set of 1000 orientations was taken randomly and each orientation was given a volume fraction according to the texture function. The thermal and elastic properties of singlecrystal zirconium are listed in Table 2 . The thermal strains due to a temperature variation from 923 to $298 \mathrm{~K}$ are calculated. The thermal and elastic coefficients depend on temperature. We have taken into account the variation of $\mathrm{c}_{\mathrm{ij}}$ and $\alpha_{\mathrm{ij}}$ with temperature $[5,6]$.

$$
\begin{array}{lllllll}
\boldsymbol{\alpha}_{11}\left(=\boldsymbol{\alpha}_{22}\right) & \boldsymbol{\alpha}_{33} & \mathbf{C}_{11} & \mathbf{C}_{33} & \mathbf{C}_{44} & \mathbf{C}_{12} & \mathbf{C}_{13} \\
9.9 & 12.0 & 143.5 & 72.5 & 65.4 & 164.9 & 32.1
\end{array}
$$

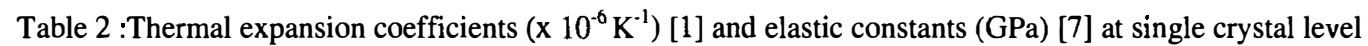
and at room temperature.

\section{III.2. Mechanical residual stresses}

We use an incremental elastoplastic self-consistent scheme to simulate the mechanical loading. At each strain increment, the non-linear behaviour is approximated by the tangent behaviour. The stress and strain rates, $\dot{\sigma}$ and $\dot{\boldsymbol{\varepsilon}}$, of each grain are linearly linked by an elastoplastic tensor $\mathbf{l}$. This tensor accounts for the plastic and elastic anisotropy of the grains and the hardening effects of the deformation systems during plasticity.

The tensor $I$ has the form :

$$
l=c-\sum_{h, g} c . R^{h} . .\left(R^{g} . . c . . R^{h}+H^{g h}\right)^{-1} . . R^{g} . . c
$$


where $\mathrm{H}$ is the hardening matrix and $\mathbf{R}^{\mathbf{g}}$ is the Schmid tensor of a system $\mathrm{g}$. The summation is performed over all the active systems $h$ and $g$.

At macroscopic level, the relation between the macroscopic stress rate and strain rate is given by a similar relation with the introduction of tensor $\mathbf{L}$.

$\dot{\boldsymbol{\sigma}}$ and $\dot{\boldsymbol{\varepsilon}}$ of each grain are linked to $\dot{\boldsymbol{\Sigma}}$ and $\dot{\mathbf{E}}$ by an interaction tensor $\mathbf{L}^{*}$ function of an Eshelby tensor taking into account the intrinsic elastic and plastic anisotropy of the HEM as well as the anisotropy induced by the plastic flow. It is a function of $\mathbf{L}$, the shape and the orientation of each grain :

$\dot{\boldsymbol{\sigma}}-\dot{\boldsymbol{\Sigma}}=\mathbf{L} . .\left[\mathbf{I}-\mathbf{S}^{\mathrm{esh}-1}\right] . .(\dot{\boldsymbol{\varepsilon}}-\dot{\mathbf{E}})=-\mathbf{L}^{*} . .(\dot{\boldsymbol{\varepsilon}}-\dot{\mathbf{E}})$

The overall elastoplastic tensor $\mathbf{L}$ is a weighted average of the mesoscopic tensor $\mathbf{l}$ :

$\mathbf{L}=<\mathbf{l} . .\left[\mathbf{I}+\mathbf{S}^{\text {esh }} . \mathbf{L}^{-1} . . \Delta \mathbf{l}\right]^{-1}>$

Equation (3) is a non linear implicit equation because $\mathbf{S}^{\text {esh }}$ depends on the unknown $\mathbf{L}$. The Eshelby tensor is calculated by an integral equation [8] which takes into account the plastic anisotropy. Equation (3) is solved by iteration. Once $\mathbf{L}$ is known, by specifying an overall stress or strain, the model can give the corresponding stress or strain tensors for each orientation. Thus, we can describe the mechanical response of the polycrystal at mesoscopic scale.

For hexagonal materials, like zirconium, because of the relatively strong crystallographic anisotropy, several modes may be active : slip and/or twinning systems. In such materials, the prismatic glide $\{10 \overline{1} 1\}, 11 \overline{2} 0\rangle$ is reported to be the main active deformation mode. First-order pyramidal slip $\{10 \overline{1} 1\}\} 11 \overline{2} 3\rangle$ and basal slip $\{0002\}\langle 11 \overline{2} 0\rangle$ are generally presented as secondary slip modes [8]. At room temperature, twinning has also been observed in zirconium samples $[9,10]$. Twinning of the $\{10 \overline{1} 2\}$ and $\left\{1 \overline{2}_{1}\right\}$ types are expected in extension along the $\overrightarrow{\mathrm{c}}$ axis whereas twinning of the $\{11 \overline{2} 2\}$ and $\{10 \overline{1} 1\}$ types are expected in compression along the $\vec{c}$ axis.

In the model, critical resolved shear stresses (CRSS) and the hardening law for slip and twinning are considered as controlling parameters. As their values depend on many factors (oxygen content, grain size, temperature...), they are considered as unknown. Consequently, they are determined through a fitting of the predicted behaviour on the experimental tensile curve in RD.

\section{Results And Comparaison Between Model And Experiment}

\section{IV.1. Mechanical response}

The initial CRSS are taken as identical for all systems of a system type. The deformation systems introduced in the model are assumed to be : prismatic slip, first-order pyramidal slip and $\{10 \overline{1} 2\}$ twinning. In this work, we considered a linear hardening law, for simplicity, the coefficient $\mathrm{H}^{\mathrm{gr}}$ is equal to $\mathrm{H}^{\mathrm{gg}}$ for any deformation modes $\mathrm{r}: \dot{\tau} \mathrm{g}=\mathrm{H}^{\mathrm{g}} \sum_{\mathrm{r}} \dot{\gamma}^{\mathrm{r}}$, i.e., latent hardening is equal to the selfhardening. The CRSS obtained are : $\tau=120 \mathrm{MPa}$ for prismatic mode, $\tau=200 \mathrm{MPa}$ for first-order pyramidal mode and $\tau=220 \mathrm{MPa}$ for tensile twinning. The hardening coefficients were found to be $140 \mathrm{MPa}$ for prismatic slip, $200 \mathrm{MPa}$ for pyramidal slip and $240 \mathrm{MPa}$ for twin mode. The CRSS for the prismatic systems is determined to reproduce the experimental yield stress in the RD. The CRSS values are adjusted to give a good description of the tensile test performed in the RD of the sheet. The hardening coefficients are chosen to be consistent with the slope of the experimental curve in the RD of the sample. The obtained parameters are then taken for the simulation of the tensile test in the TD.

The experimental tests show several differences between the two directions : the yield stress is higher, the elastoplastic transition is faster and the curve shows a plateau at $0.6 \%$ strain in the transverse direction. The measured yield stresses are $205 \mathrm{MPa}$ and $290 \mathrm{MPa}$ (stress differential of $85 \mathrm{MPa}$ ) in the RD an TD respectively. The corresponding Young's modulus are $93 \mathrm{GPa}$ and 96 
GPa. These values are similar because of the low elastic anisotropy. With the model developed here, the predicted Young's modulus are $93 \mathrm{GPa}$ and $95 \mathrm{GPa}$ in agreement with the experimental ones. The stress differential can be attributed to thermal stresses [2]. The predicted yield stresses are $205 \mathrm{MPa}$ and $275 \mathrm{MPa}$ in the RD an TD respectively. When no thermal stresses are assumed, the model predicts a low stress differential $(<15 \mathrm{MPa})$ which could be attributed to texture.

For the test along the $\mathrm{RD}$, the elastoplastic transition starts with the activation of prismatic slip. At $0.7 \%$ strain, pyramidal slip is activated and when the deformation reaches $1.3 \%$ deformation, the polycrystal is fully plastic. This sequence explains correctly the experimental loading slope. At $1 \%$ deformation, the proportions of activated systems are: $83 \%$ for prismatic mode, $16.5 \%$ for pyramidal slips and $0.5 \%$ for tensile twinning. Finally, we obtained a reasonable distribution in agreement with the experimental observations: prismatic glide is the main active mechanism, pyramidal slip is a secondary slip mode and twinning contributes very few to plastic deformation. When tension is simulated in the TD, the yield stress is higher and the plastic deformation begins by the activation of prismatic slip. At $0.4 \%$ strain, pyramidal systems become active and the material is fully plastic at about $0.9 \%$. At $1 \%$, the distribution of activated systems is : $75 \%, 24.2 \%$ and $0.8 \%$ for the prismatic, pyramidal and tensile twin respectively. The model fails to reproduce correctly the plateau in the curve. Turner $\&$ al [11] attributed this part to the relaxation of stresses by twinning. In our model, this phenomenon is incorporated, but we found that plastic deformation due to twinning is less than $1.0 \%$ and this result is coherent with experimental observations. Consequently, it seems clear that twinning cannot explain the plateau of the curve in the TD. If we take lower values of CRSS or hardening coefficients that doesn't modify this tendency. Higher dislocation annihilation with a solicitation along TD could be explain this phenomenon.

\section{IV.2. X-ray diffraction results}

Strains measurements have been made with two plane families : $\{10 \overline{1} 4\}$ and $\{20 \overline{2} 2\}$ planes. The stress was obtained from the $\sin ^{2} \psi$ relation. In the present section, it should be remembered that, due to the homogeneous macroscopic plastic flow, there is no macroscopic residual stress. The measured and simulated stresses are relative to the diffracting volume, i.e. to groups of crystallites with specific orientation. The mentioned stresses are thus pseudo-macroscopic stresses. X-ray analysis has been made with a removed thickness of $100 \mu \mathrm{m}$ by electro polishing. Figure 2 presents pseudo-macroscopic stress after unloading as a function of total deformation (prestrain) in our samples using the $\{10 \overline{1} 4\}$ and $\{20 \overline{2} 2\}$ planes with $\phi=0^{\circ}$ and a solicitation along the $R D$. The two planes exhibit an opposite behaviour : $\{10 \overline{1} 4\}$ plane is in traction and $\{20 \overline{2} 2\}$ plane is in compression with a stress value that increases with the amount of prestrain. At $2 \%$ strain, $\sigma$ value reaches $30 \mathrm{MPa}$ for $\{10 \overline{1} 4\}$ plane and $-100 \mathrm{MPa}$ for $\{20 \overline{2} 2\}$ plane. X-ray measurements show the existence of plastic anisotropy. For comparison, in cold rolled zircaloy-4 cladding tubes [12], the stresses obtained by XRD depend strongly on the analysed plane family (+168 MPa for the $\{10 \overline{1} 4\}$ plane and $-193 \mathrm{MPa}$ for the $\{20 \overline{2} 2\}$ plane). This significant difference is also observed in the case of zirconium.

\section{IV.3. Predicted mesoscopic strains}

The next step will be to validate the assumptions on the deformation modes activated in our calculations. For that, the confrontation between stress measurements with diffraction techniques on these samples and simulation at mesoscopic level has been achieved.

Simulations have been performed on a polycrystal with different combinations of plastic modes (pyramidal or basal slip as the main active deformation mode). The mesoscopic stresses were then averaged and projected on the $\phi \psi$ direction to simulate the X-ray behaviour. From the slope of $\varepsilon_{\phi \psi}$ curves, we calculated an estimation of the pseudo-macroscopic residual stresses as a function of total prestrain. It was found that, only when prismatic glide was taken as the main deformation 
mode, the simulations could match the experimental results : traction for $\{10 \overline{1} 4\}$ and compression for $\{20 \overline{2} 2\}$ planes. Figure 2 presents this evolution. Stresses values are different for the two studied planes. Although the predictions are in qualitative agreement with experimental evidence, the residual stresses are overpredicted by the self-consistent model. It is a well-known feature of this model [13] which is too "stiff" because it doesn't take into account the fluctuations of moduli in the matrix and the inclusion due to the nonlinearity of the mechanical behaviour [14]. In our case, the model overestimates the observed residual stress by at least a factor two.

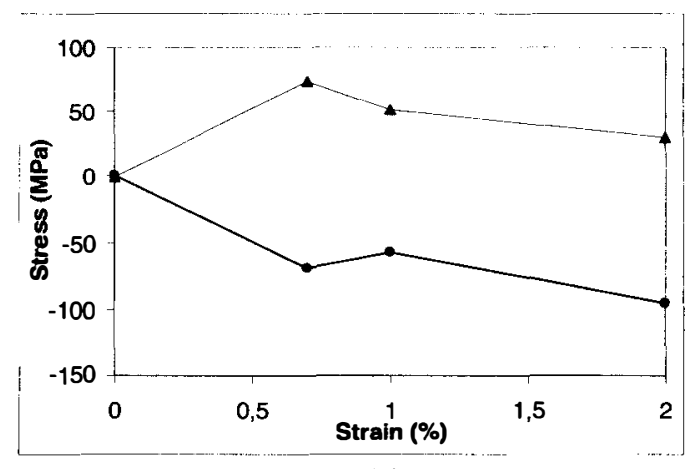

(a)

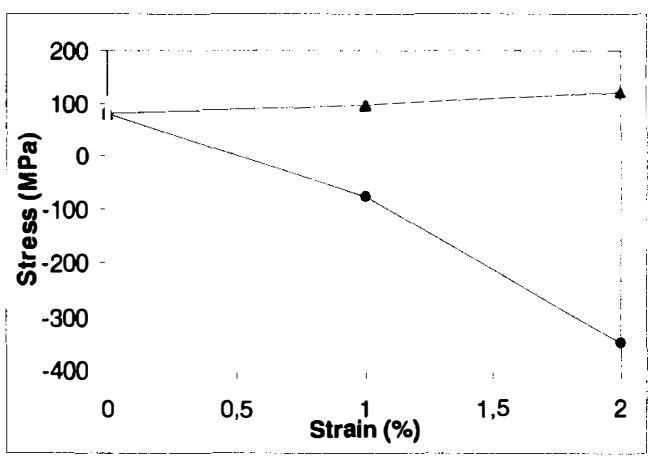

(b)

Figure 2 : Evolution experimental (a) and calculated (b) of $\sigma$ with total strain for $\phi=0^{\circ} \cdot \bullet:\{20 \overline{2} 2\}$ plane, $\Delta:\{10 \overline{1} 4\}$ plane. Axis loading is parallel to RD.

\section{Conclusions}

In this study, the thermal residual stresses in a rolled $\alpha-\mathrm{Zr}$ using a self-consistent model have been evaluated and compared with $\mathrm{X}$-ray diffraction results. A good agreement between the two methods has been obtained. An elastoplastic self-consistent approach has been developed in order to modelise the mechanical response of rolled $\mathrm{Zr}$ under uniaxial loading. We showed that thermal stresses can explain the stress differential between RD and TD of the sample and that the elastoplastic transition can be explained by texture and internal stresses. The choice of prismatic slip as principal deformation mode can explain the opposite pseudo-macrostresses values for the two studied planes. These predicted results can be only obtained for a single set of slips modes and hardening parameters. This analysis shows that X-ray diffraction stress analysis could constitute an effective validation or identification of a modelization.

\section{References:}

[1] Mac Ewen S.R., Tomé C., Faber J., Acta Mater., Vol. 37, n³, 1989, pp.979-989.

[2] Gloaguen D., François M., Guillen R. Royer J., Acta Mat., Vol. 50, n4, 2002, pp. 871-880.999

[3] Hill R., J. Mech. Phys. Solids, Vol. 13, 1965, pp.89-101.

[4] Lipinski P., Berveiller M., Int. Journal of Plasticity, Vol. 5, 1989, pp.149-172.

[5] Fisher E.S., Renken C., Phys. Review, n¹35, 1964, pp.484-494.

[6] Goldak J., Lloyd L.T., Barrer C.S., Phys. Review, Vol. 144, n², 1966, pp478-483.

[7] Simmons G., Wang H., Single crystal elastic constants and calculated aggregate properties, Cambridge MA; M.I.T. Press, 1971.

[8] Tenckhoff E.,Deformation Mechanisms, Texture, and Anisotropy in Zirconium and Zircaloy, STP 966, 1916 Race Street, Philadelphia, PA 19103. 1988.

[9] Akhtar A., Met. Trans., Vol.6A, 1975, pp.1 105-1113.

[10] Akhtar A., Journal of Nucl. Mat., Vol. 47, 1973, pp.79-86.

[11] Turner P.A., Christodoulou N., Tomé C.N., Int. Journal of Plasticity, Vol. 11, n³, 1995, pp.251-265.

[12] Guillen R., Cossu C., François M. Girard E., Journal of Nucl. Mat., Vol. 255, 1998, pp.174-179.

[13] Krier J.,Doctoral thesis, University of Metz, 1993.

[14] Zaoui A., Masson R., Mat. Science and Engineering, Vol. A285, 2000, pp.418-424. 